\title{
Evaluation of glycerol-preserved bone allografts in cervical spine fusion: a prospective, randomized controlled trial
}

\author{
R. Scott Graham, MD, ${ }^{1}$ Brian J. Samsell, BS, ${ }^{2}$ Allison Proffer, BS, ${ }^{2}$ Mark A. Moore, PhD, ${ }^{2}$ \\ Rafael A. Vega, MD, PhD, ${ }^{1}$ Joel M. Stary, MD, PhD, ${ }^{1}$ and Bruce Mathern, MD1 \\ 1Department of Neurosurgery, Virginia Commonwealth University Health Systems, Medical College of Virginia, Richmond; and \\ ${ }^{2}$ Institute of Regenerative Medicine, LifeNet Health, Virginia Beach, Virginia
}

\begin{abstract}
OBJECT Bone allografts used for interbody spinal fusion are often preserved through either freeze drying or lowtemperature freezing, each having disadvantages related to graft preparation time and material properties. In response, a glycerol preservation treatment has been developed to maintain the biomechanical properties of allografts at ambient temperatures, requiring no thawing or rehydration and minimal rinsing prior to implantation. The authors conducted a prospective randomized study to compare the clinical results of glycerol-preserved Cloward dowels and those of freezedried Cloward dowels in anterior cervical discectomy and fusion. The primary outcome measures were evidence of fusion and graft subsidence, and the secondary outcome measures included adverse events, pain, and neck disability scores.
\end{abstract}

METHODS Of 106 patients, 53 (113 levels of surgery) were randomly assigned to the glycerol-preserved graft group and 53 (114 levels of surgery) to the freeze-dried graft group. Subsidence was assessed at 3 and 6 months after implantation. Evidence of fusion was evaluated radiographically at 6 months postimplantation. Subsidence was quantitatively assessed based on physical measurements obtained from radiographs by using calibrated comparators, whereas fusion was also evaluated visually. Surgeons were blinded to treatment type during visual and physical assessments of the patients and the radiographs.

RESULTS No one in either group had evidence of complete nonunion according to radiographic evaluation at the 6-month follow-up. Average subsidence for all graft-treated levels was $2.11 \mathrm{~mm}$ for the glycerol-preserved group and $2.73 \mathrm{~mm}$ for the freeze-dried group at the 3-month follow-up and 2.13 and $2.83 \mathrm{~mm}$ at the 6 -month follow-up, respectively. The 2 treatment groups were statistically equivalent $(p=0.2127$ and 0.1705 for the 3 - and 6 -month follow-up, respectively). No differences were noted between the graft types in terms of adverse event incidence or severity.

CONCLUSIONS Glycerol-preserved bone allografts exhibit fusion results and subsidence values similar to those of their freeze-dried counterparts, potentially more favorable biomechanical properties, and significantly shorter preparation times.

Clinical trial registration no.: NCT00344890 (clinicaltrials.gov)

http://thejns.org/doi/abs/10.3171/2014.9.SPINE131005

KEY WORDS Cloward dowel; allograft; anterior cervical fusion; glycerol preservation; technique

$\mathrm{C}$ ERVICAL spondylosis or trauma can evolve into radiculopathy or myelopathy often requiring surgical intervention. ${ }^{13,29,34}$ Anterior cervical discectomy and fusion $(\mathrm{ACDF})$ procedures are performed to treat these conditions and involve the use of synthetic or structural bone interbody spacers. ${ }^{4,34}$
While human bone allografts have demonstrated success in ACDF procedures, their ease of use is limited as compared with that of ready-to-use synthetic cages stored at ambient temperatures. This relates to the traditional provision of bone allografts in either freeze-dried or deep-frozen form. If freeze dried, the dehydrated allograft must be

ABBREVIATIONS ACDF = anterior cervical discectomy and fusion; CTDR = cervical total disc replacement; NDI = Neck Disability Index; VAS = visual analog scale. SUBMITTED November 14, 2013. ACCEPTED September 22, 2014.

INCLUDE WHEN CITING Published online October 31, 2014; DOI: 10.3171/2014.9.SPINE131005.

DISCLOSURE The authors report no conflict of interest concerning the materials or methods used in this study or the findings specified in this paper. Dr. Moore and Mr. Samsell are employees of LifeNet Health. Ms. Proffer is a former employee of LifeNet Health. LifeNet Health has supplied the Medical College of Virginia with materials and funding for this study. The investigators received no direct financial benefit. Virginia Commonwealth University/Medical College of Virginia personnel performed the clinical aspects of the study including coordination, surgery, patient follow-up, and radiographic analysis of fusion. LifeNet Health research personnel assisted in study design, data analysis, and portions of the technical writing. 
reconstituted before implantation. In addition to the extra operating room time required, tissue brittleness and weakness can still occur as a result of the freeze-drying process, even if the graft is rehydrated per instructions. ${ }^{5,11,27}$ Subsequent cracking of a graft upon forceful insertion can be expensive to rectify and may even go undetected during implantation. The other alternative-deep freezing and storing of tissue at $-40^{\circ} \mathrm{C}$ to $-80^{\circ} \mathrm{C}$-may prevent brittleness and tissue degradation but increases shipping costs and may require storage in validated, monitored, ultralow-temperature freezers. Moreover, the time required for thawing frozen tissue can increase case time, and an inadvertently thawed graft would need to be discarded even if it were unused or unopened.

In addressing these limitations, a glycerol preservation technology has been developed to avoid the potential brittleness of freeze-dried allografts as well as the subzerotemperature shipping and storage requirements of frozen grafts. ${ }^{19}$ Glycerol preservation uses a thin protective coat of glycerol to both preserve the tissue and keep it fully hydrated (Moore M, Crouch K, O'Neal A, et al., presented at the BioInterface Annual Symposium and Exhibition, 2004). The end result is an allograft that can be maintained at ambient temperatures until use. ${ }^{19}$ While glycerol is used as a carrier in bone void filler products, such as Grafton and Optium DBM, that are used in the spine, the clinical significance of glycerol impregnation on the properties of a structural intervertebral spacer remains unknown. Thus, we initiated a study to test how a glycerol-preserved allograft would perform in an ACDF series.

Previously, we reported subsidence measurements for freeze-dried bone in ACDF procedures in which Cloward dowels were used as the spacer. ${ }^{30}$ Since that study was performed, the same manufacturer (LifeNet Health) developed the glycerol-preserved allograft described here. We sought to determine how these structural bone allografts, preserved at room temperature with glycerol, would clinically perform in comparison with the freeze-dried alternative. Thus, using our standard clinical methodology, we initiated a prospective randomized study to compare ACDF surgical outcomes after implanting either the glycerolpreserved or the traditional freeze-dried Cloward dowels. These results may be applicable to other structural or nonstructural glycerol-preserved allografts used in the spine.

\section{Methods}

\section{Study Design and Objectives}

This study was a prospective, randomized, blinded clinical evaluation comparing glycerol-preserved and freezedried Cloward dowels in ACDF surgery for cervical radiculopathy or myelopathy. Study design, methods, and informed consent were reviewed and approved by an institutional review board through the Virginia Commonwealth University Health Systems, the study was registered with the ClinicalTrials.gov database (http://clinicaltrials.gov), and the study registration no. is NCT00344890. There were 5 implantation surgeons (R.S.G., B.M., H.F.Y., W.C.B., and K.H.; the first 2 surgeons are authors on this paper). The study and surgical technique are largely modeled on those by Tye et al., ${ }^{30}$ who evaluated subsidence rates for ACDF surgery using freeze-dried Cloward dowel allografts. Objectives of the present study included statistical comparison of subsidence measurements at 3 and 6 months after implantation and qualitative assessment of graft fusion at 6 months. We hypothesized that the experimental group (glycerol-preserved allografts) would not have outcomes significantly inferior to those of the control group (freezedried allografts).

\section{Surgical Assessment Methods}

Subsidence was quantitatively measured from radiographs. Plate and fusion lengths were measured using postimplantation (postoperative Day 1) lateral radiographs and were compared with cervical spine radiographs obtained during the 3- and 6-month follow-up visits. The length of the fusion segment (FL) was determined by multiplying the known plate length (KPL) by the measured fusion length (MFL) and dividing by the measured plate length (MPL; FL $=[\mathrm{KPL} \times \mathrm{MFL}] / \mathrm{MPL})$. The measured fusion plate length was measured from the midpoint between the anterior and posterior aspects of the endplates. A blinded study surgeon qualitatively assessed evidence of fusion on radiographs at 6 months after implantation. The 6-month radiographs included neutral anterior/posterior, lateral flexion, lateral extension, and neutral lateral. In addition to the radiographs, a blinded study surgeon also assessed each patient for long track signs, deep tendon reflexes, sensory responses, and motor strength. The study surgeon was blinded to treatment type during all visual and physical assessments of the patients and radiographs.

\section{Patient Population}

The study was originally designed for the enrollment of 120 patients, 60 to receive glycerol-preserved allografts and 60 to receive rehydrated freeze-dried allografts, with each arm stratified according to the expected number of cervical discs to be fused. This enrollment number was based on what was deemed necessary to achieve statistical significance of equivalence using statistics derived from Tye et al. ${ }^{30}$ However, we also recognized that statistical equivalence might be achieved before reaching this number, leading to early termination of enrollment. All patients were treated at the Virginia Commonwealth University Medical Center. The study coordinator selected a computer-generated, randomized treatment arm at the time of surgery. Treatment assignments were unknown to the investigator or study coordinator prior to surgery. The resultant study included only 106 patients because we did, in fact, achieve statistically meaningful results prior to reaching the original target enrollment (Fig. 1). It was determined, since the study objectives had already been achieved, that no patient benefit would be obtained by continuing to enroll patients in the 2-armed study, and thus the study was truncated. All patients who had 3-month (88 patients) and/or 6-month (86 patients) follow-ups were included in the analysis for which statistical power was achieved. As detailed in Table 1,53 patients were included in each study arm. For each treatment group, 13 patients had 1-level fusions and 4 had 4-level 


\section{Enrollment}

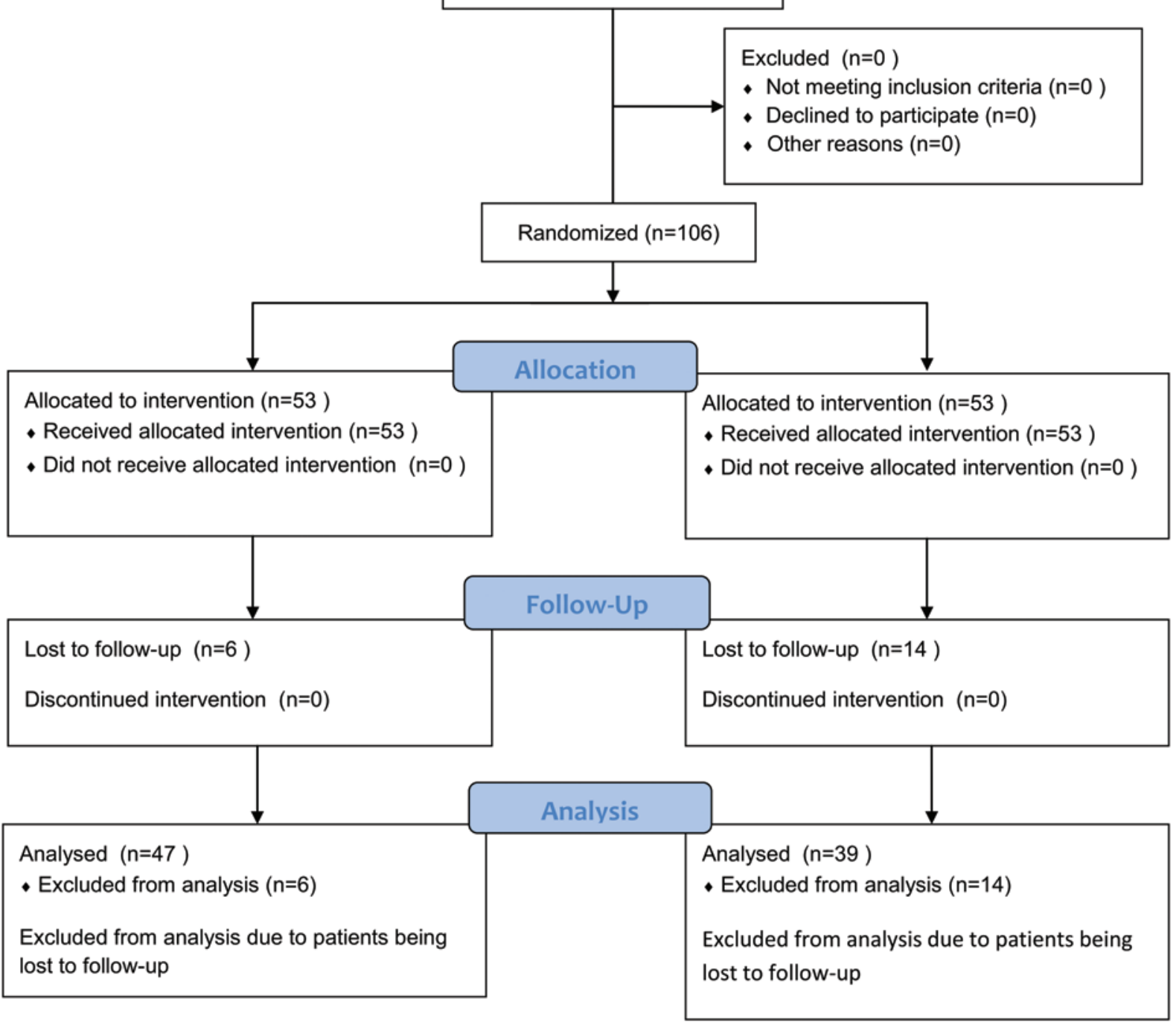

FIG. 1. CONSORT flow diagram showing the number of patients in each treatment arm from start to finish of the study. Figure is available in color online only.

fusions. For the glycerol-preserved group, 24 patients had 2-level fusions and 12 had 3-level fusions. For the freezedried group, 23 patients had 2-level fusions and 13 had 3 -level fusions. The same graft treatment was used at all surgical levels for a given patient. Thus, for each group, 13 grafts were used in 1-level fusions and 16 grafts were used in 4-level fusions. In addition, 48 grafts were used in the 2-level fusions and 36 grafts in the 3-level fusions for the glycerol-preserved group, and 46 grafts were used in the 2-level fusions and 39 grafts in the 3-level fusions for the freeze-dried group. In sum, the glycerol-preserved group represented 113 levels of surgery and the freezedried group represented 114 levels.

In addition to providing voluntary informed consent, patients had to meet all inclusion criteria and have none of the exclusion criteria to be included in the study. Inclusion criteria consisted of an age between 18 and 70 years, clinically confirmed radiculopathy or myelopa- thy due to neural compression between C3-4 and C6-7, and an agreement to follow all study protocols such as treatment randomization and attendance at scheduled follow-up appointments. Exclusion criteria consisted of a previous cervical spine surgery, a multilevel fixed and/ or ankylosed cervical spine, and any other condition that would interfere with an accurate pain and/or function assessment such as rheumatoid arthritis or a progressive neuromuscular disease. Patients were excluded if preenrollment plain radiographs failed to visualize the inferior endplate of the most caudal fusion segment, thus precluding an accurate measurement of primary outcome measures. Smoking was not an exclusion criterion, and patients were not randomized according to tobacco use. However, it was noted that 11 patients were considered tobacco users -4 in the glycerol-preserved group and 7 in the freeze-dried group-and these numbers were considered too small to subanalyze. 
TABLE 1. Progress and attrition of cases in a study of glycerol-preserved and freeze-dried grafts in ACDF

\begin{tabular}{|c|c|c|c|c|c|c|c|}
\hline \multirow[b]{2}{*}{$\begin{array}{l}\text { Level } \\
\text { Fused }\end{array}$} & \multirow[b]{2}{*}{ Month } & \multicolumn{3}{|c|}{ Glycerol-Preserved } & \multicolumn{3}{|c|}{ Freeze-Dried } \\
\hline & & $\begin{array}{l}\text { Actual } \\
\text { Cases }\end{array}$ & $\begin{array}{l}\text { Cases Lost } \\
\text { to FU }\end{array}$ & $\begin{array}{c}\text { Cases Used in } \\
\text { Statistical Analysis }\end{array}$ & $\begin{array}{l}\text { Actual } \\
\text { Cases }\end{array}$ & $\begin{array}{l}\text { Cases Lost } \\
\text { to FU }\end{array}$ & $\begin{array}{c}\text { Cases Used in } \\
\text { Statistical Analysis }\end{array}$ \\
\hline \multirow{2}{*}{1} & 3 & \multirow{2}{*}{13} & 1 & 12 & \multirow{2}{*}{13} & 3 & 10 \\
\hline & 6 & & 1 & 12 & & 4 & 9 \\
\hline \multirow{2}{*}{2} & 3 & \multirow{2}{*}{24} & 3 & 21 & \multirow{2}{*}{23} & 4 & 19 \\
\hline & 6 & & 3 & 21 & & 4 & 19 \\
\hline \multirow{2}{*}{3} & 3 & \multirow{2}{*}{12} & 2 & 10 & \multirow{2}{*}{13} & 4 & 9 \\
\hline & 6 & & 2 & 10 & & 4 & 9 \\
\hline \multirow{2}{*}{4} & 3 & \multirow{2}{*}{4} & 0 & 4 & \multirow{2}{*}{4} & 1 & 3 \\
\hline & 6 & & 0 & 4 & & 2 & 2 \\
\hline \multirow{2}{*}{ Total } & 3 & \multirow{2}{*}{53} & 6 & 47 & \multirow{2}{*}{53} & 12 & 41 \\
\hline & 6 & & 6 & 47 & & 14 & 39 \\
\hline
\end{tabular}

FU = follow-up.

\section{Surgical Procedure}

The Cloward dowel surgical procedure ${ }^{8}$ used by Tye et al. ${ }^{30}$ was followed in this study. All ACDF surgeries were performed with human bone allograft Cloward dowels. The cervical spine was accessed via an anterior approach through the neck. Degenerated discs were removed and replaced with either glycerol-preserved (Preservon, LifeNet Health) or freeze-dried (LifeNet Health) allograft Cloward dowels, depending on the treatment group. Both graft types were treated with Allowash and terminally sterilized using gamma irradiation at dry ice temperatures. ${ }^{1,19}$ Per the manufacturer's instructions, the glycerol-preserved grafts were rinsed in sterile saline for at least 30 seconds, whereas the freeze-dried grafts were rehydrated in sterile saline for at least 30 minutes. Rigid internal segmental fixation was then performed via implantation of an Atlantis anterior cervical plate (Medtronic Sofamor Danek) with fixed-angle screws. The size of the plate and the length of the screw fixation were left to the discretion of the operating surgeon.

\section{Statistical Methods}

Statistical analysis was evaluated using a personal computer, Microsoft Excel, and SAS and StatView commercial statistical software packages. Analysis of fusion and plate length in comparison with subsidence was performed using a Pearson correlation coefficient. The degree of subsidence was expected to positively correlate with the plate length and the number of levels fused. Graft fusion was deemed successful or unsuccessful based on surgeon assessment. Analysis of dichotomous data was performed using Fisher's exact test or a chi-square test. A post hoc statistical power analysis indicated that 38 patients were needed in each treatment group to achieve a 92.5\% confidence interval and 0.075 level of significance based on 6-month mean subsidence measurements.

\section{Results}

At 3 months postimplantation (Table 1), 6 patients in the glycerol-preserved group and 12 in the freeze-dried group had been lost to follow-up. There was no significant difference in subsidence between the treatment groups according to radiographic assessment by a blinded surgeon (Fig. 2). No patients in either group had evidence that the grafts had moved, loosened, dislodged, or fractured or had another problem not specified.

At the 6-month follow-up, the treating surgeon qualitatively assessed all 47 patients in the glycerol-preserved group and all 39 in the freeze-dried group (Fig. 3) as having achieved all-level fusions, as reported on the appropriate study case report form. This qualitative assessment of fusion was made at the 6-month evaluation, which was based on radiographic criteria including the absence of segmental motion on flexion and extension views, the appearance of graft incorporation, and the absence of radiographic lucencies surrounding grafts and hardware. Computed tomography scanning or other more advanced methods were not used. According to the methods applied, none of the reported patients in either group had nonunions. A blinded nontreating surgeon reviewed the radiographs to measure subsidence and determine fusion status using the same criteria. The independent assessment revealed one patient in the glycerol-preserved group who exhibited persistent movement upon flexion and extension and one patient, a tobacco user in the freezedried group, who exhibited pseudofusion (Table 2). These particular patients were asymptomatic and underwent no further surgeries. Overall, we considered the results to constitute an assessed fusion rate $>95 \%$, regardless of the study arm. Moreover, there was no significant difference in subsidence between treatment groups according to radiographic assessment by a blinded surgeon. Subsidence measurements are presented as a function of the number of levels of surgery and are reported for both the 3- and 6-month follow-up in Fig. 2.

The Neck Disability Index (NDI) and visual analog scale (VAS) scores for the neck, left arm, and right arm were collected from 93 patients at the screening and 6 weeks, 3 months, or 6 months postimplantation. Both treatment groups showed an initial dramatic improvement (reductions) in all 4 scores (Figs. 4 and 5). Patients 

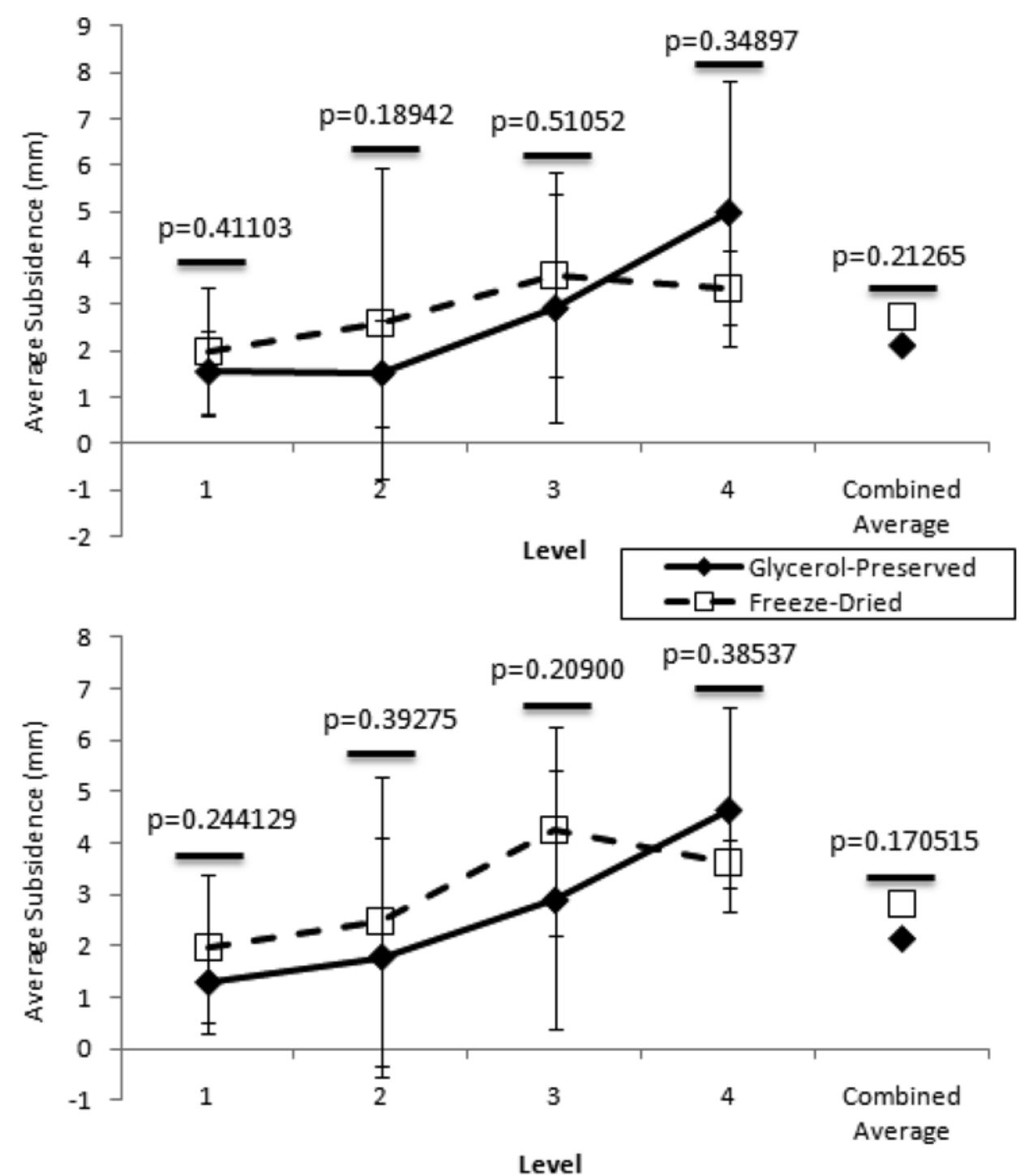

FIG. 2. Average subsidence at 3 (upper) and 6 (lower) months postoperatively, calculated according to fusion level. Error bars reflect the standard deviation. All 4 levels for glycerol-preserved and freeze-dried grafts show statistical equivalence for average subsidence, since all of the calculated $p$ values are greater than 0.05 ; that is, there was no statistically significant difference between glycerol-preserved and freeze-dried grafts at a 95\% confidence level. Also included is the combined subsidence average regardless of level.

with glycerol-preserved allografts had scores similar to those in patients with freeze-dried grafts but also showed a trend toward a greater percentage of improvement in all 4 scores by the 6 -month follow-up. This difference in percentage improvement for the glycerol-preserved grafts was statistically significant for the NDI scores $(\mathrm{p}=0.035)$; however, this may not be clinically relevant. Regardless, the glycerol-preserved allografts yielded results at least equivalent to those for the freeze-dried controls.

At each follow-up, the examination nurse and physician sought information on adverse events through examination and questioning. Patients were encouraged to report any physical symptoms at that time and in between scheduled visits as warranted. All adverse events that occurred during the study period (6 months from the date of surgery) were recorded in detail on a designated collection form. Fifty-nine patients $(55.7 \%$ of the
106 study subjects) experienced at least one of the 108 adverse events reported (Table 2). Typical reported events included dysphagia and pain in the neck area or along the arms, shoulders, and back. Many of the reported events were obviously unrelated to the type of cervical implant, for example, torn rotator cuff, foot fracture, panic attacks, and so forth. Of those 108 adverse events, 12 (11.1\%) were considered possibly graft or procedure related. Nine (8.5\%) of the 106 study participants experienced an adverse event that was possibly graft related. These events included neck, arm, and shoulder pain $(3.8 \%$ of patients and $3.7 \%$ of all adverse events) and subsidence (3.8\% of patients and $3.7 \%$ of all adverse events). One patient experienced segmental kyphosis 1 level below a fusion that had been complicated by a deep wound infection. Another patient exhibited pseudofusion of the lowest level of a 3-level anterior cervical fusion that may have been graft 

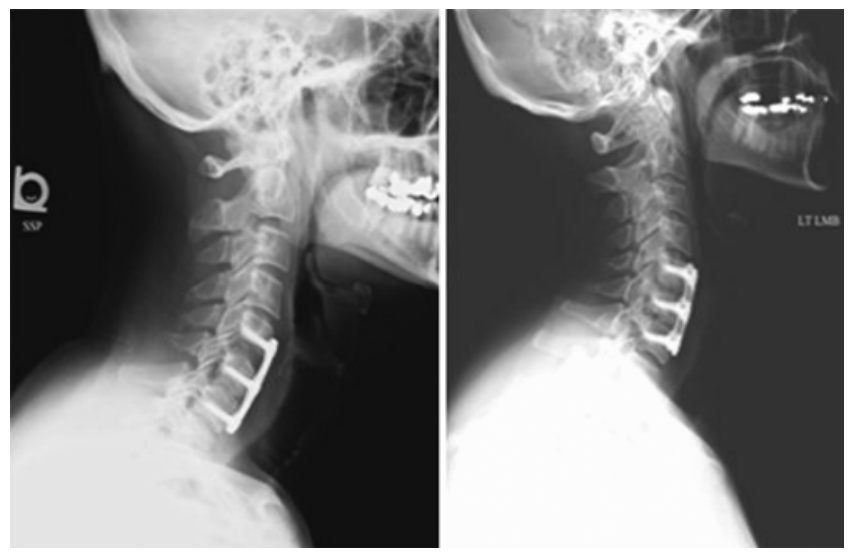

FIG. 3. Representative radiographs of freeze-dried (left) and glycerolpreserved (right) grafts at the 6-month follow-up show fusion in both treatment groups.

related. Both of these patients had received freeze-dried grafts. Persistent movement of the lower level on flexion/ extension was noted in one of the patients in the glycerolpreserved group, which may have been graft related. Of the adverse events that were possibly graft related, their incidence was identical for each of the 2 treatment groups, representing $5.6 \%$ (6) of the total adverse events in each study arm. Of the 108 adverse events reported, 96 (88.9\%) were deemed to be unrelated to the graft. Fifty $(47.2 \%)$ of the 106 study participants experienced an adverse event that was not graft related. For the 96 adverse events that were not graft related, 43 (44.8\%) were reported for patients who had received glycerol-preserved grafts and $53(55.2 \%)$ were reported for patients who had received freeze-dried grafts, again indicating no greater incidence of adverse events with the glycerol-preserved grafts.

\section{Discussion}

Glycerol preservation allows allograft tissue to be stored without freeze drying and at ambient temperatures. After briefly rinsing before implantation ( $<30$ seconds), the graft contains minimal glycerol and is ready for use. In comparison, widely used demineralized bone matrixbased bone void filler products, such as Optium DBM and Grafton, contain approximately 70\% glycerol upon implantation. Moreover, glycerol is commonly used as a preservation treatment for skin allografts in European tissue banks, ${ }^{10,17,23,33}$ especially in the Euro Skin Bank that developed this method for skin allografts. ${ }^{24}$ Consistent with this common use of glycerol in medical implants, our

TABLE 2. Summary of all adverse events recorded in the course of the study

\begin{tabular}{|c|c|c|}
\hline \multirow[b]{2}{*}{ Adverse Event } & \multicolumn{2}{|c|}{ No. of Cases (\%) } \\
\hline & Glycerol-Preserved Graft & Freeze-Dried Graft \\
\hline \multicolumn{3}{|l|}{ Severe event, possibly graft related* } \\
\hline Neck pain & $1(0.9)$ & 0 \\
\hline Segmental kyphosis level below the fusion & 0 & $1(0.9)$ \\
\hline Deep wound infection & 0 & $1(0.9)$ \\
\hline Subtotal & $1(0.9)$ & $2(1.8)$ \\
\hline \multicolumn{3}{|l|}{ Mild-moderate event, possibly graft related* } \\
\hline Neck pain & $1(0.9)$ & 0 \\
\hline Neck \& shoulder pain & 0 & $1(0.9)$ \\
\hline Arm pain & $1(0.9)$ & 0 \\
\hline Subsidence & $2(1.8)$ & $2(1.8)$ \\
\hline Persistent movement of lowest level on flexion/extension & $1(0.9)$ & 0 \\
\hline $\begin{array}{l}\text { Pseudofusion of lowest level of 3-level anterior cervical } \\
\text { fusion }\end{array}$ & 0 & $1(0.9)$ \\
\hline Subtotal & $5(4.6)$ & $4(3.7)$ \\
\hline \multicolumn{3}{|l|}{ Event, not graft related* } \\
\hline Neck pain & $6(5.6)$ & $6(5.6)$ \\
\hline Dysphagia & $3(2.8)$ & $4(3.7)$ \\
\hline Neck \& shoulder pain & $6(5.6)$ & $1(0.9)$ \\
\hline Neck \& arm pain & $2(1.8)$ & $4(3.7)$ \\
\hline Back pain & $2(1.8)$ & $3(2.8)$ \\
\hline Arm pain & 0 & $3(2.8)$ \\
\hline Shoulder pain & $2(1.8)$ & $1(0.9)$ \\
\hline Radiculopathy & $1(0.9)$ & $2(1.8)$ \\
\hline Hand numbness & $2(1.8)$ & $0(0)$ \\
\hline Miscellaneous (1 occurrence each) & $19(17.6)$ & $29(26.8)$ \\
\hline Subtotal & $43(39.8)$ & $53(49.1)$ \\
\hline
\end{tabular}

* As assessed by the Data Safety Monitoring Board or examining physician. 

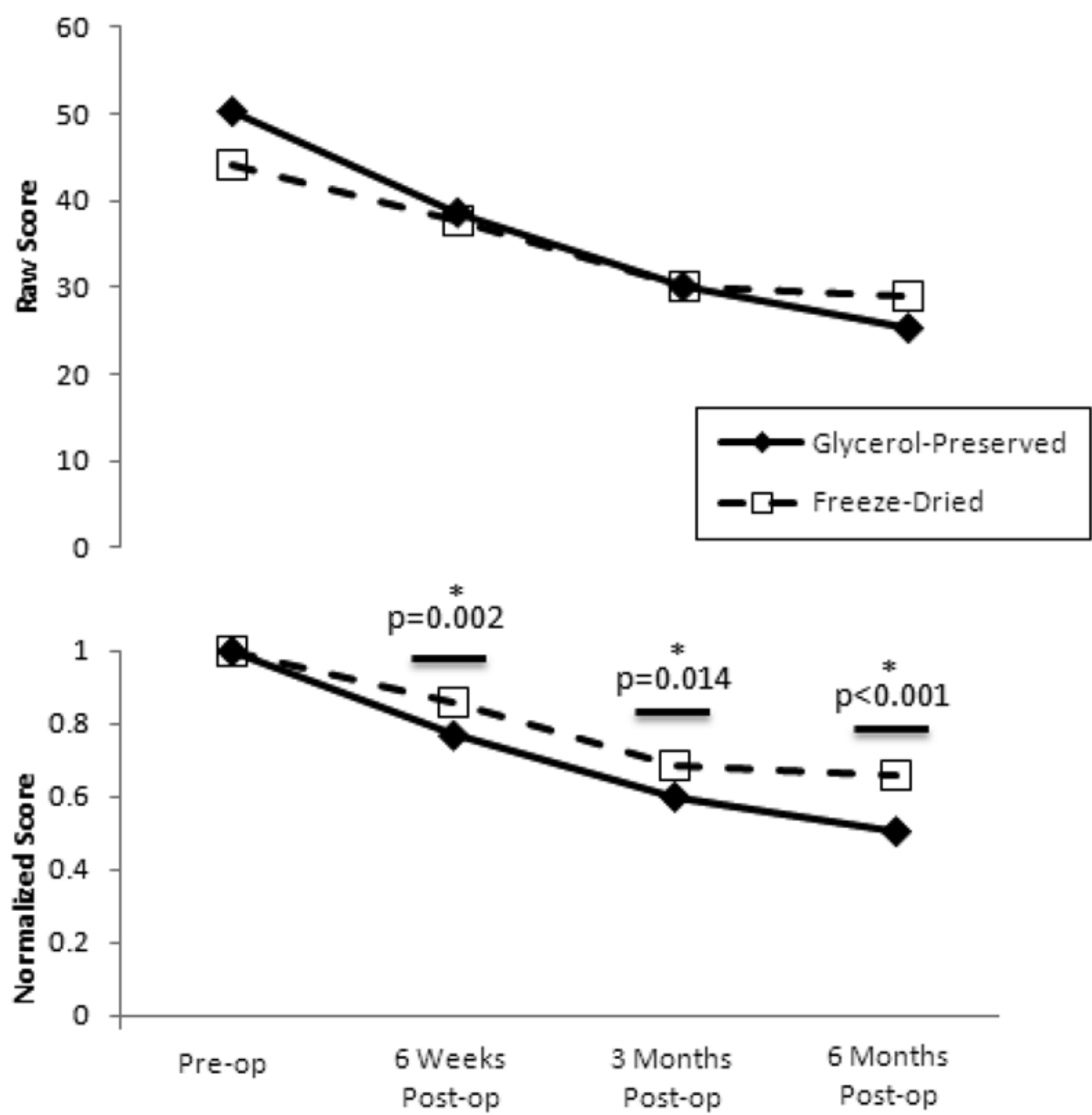

FIG. 4. Neck Disability Index scores for glycerol-preserved and freeze-dried allograft groups. Upper: Raw NDI scores indicating a trend toward lower postoperative scores for both treatment groups. Lower: Raw NDI scores normalized to prescreening scores. The normalized scores showed statistically significant improvement in NDI scores at every follow-up time point in the glycerolpreserved group over the freeze-dried group. Asterisk indicates statistical significance toward a lower NDI score with glycerolpreserved allografts.

results indicated no incidence of glycerol-related neurological dysfunction in 53 patients who received glycerolpreserved grafts at a total of 113 separate levels of surgery.

Graft and plate complications can be expected with anterior cervical spine surgery. Studies have indicated that $28 \%-57 \%$ of patients who have undergone anterior cervical spine surgery will experience some degree of postoperative dysphagia. ${ }^{12,15,16,26}$ The reported incidence of dysphagia following anterior cervical spine surgery varies because it appears that medical records, as compared with patient surveys, substantially underreport dysphagia. ${ }^{12}$ The reported incidence of radiculopathy during or after anterior cervical spine surgery is $0.2 \%-3.2 \% .^{2,14,28}$ These published rates for both dysphagia and radiculopathy compare favorably with the incident rates in the present study of glycerolpreserved (2.8\% and $0.9 \%$, respectively) and freeze-dried allografts (3.7\% and $1.8 \%$, respectively). The patients with adverse events that were possibly graft related progressed well, and the incidence of adverse events is consistent with this type of surgery. Additionally, both treatment groups had the same number of patients with possibly graft-related adverse events, which suggests glycerol-preserved grafts are as safe as traditional freeze-dried grafts.

As reported, both groups exhibited equivalent high fusion rates at 6 months and similar adverse event rates. The average 6-month subsidence measurements, $2.13 \mathrm{~mm}$ for the glycerol-preserved group and $2.83 \mathrm{~mm}$ for the freeze-dried group, compare favorably with the reported literature rates of $2.25 \mathrm{~mm}^{30}$ and $3 \mathrm{~mm}^{3}$ for combined multilevel fusion allograft groups. Moreover, both treatment groups had NDI and VAS scores consistent with those in additional studies investigating allograft treatment for ACDF.7,20,21,25,31 In the present study, the trend toward greater improvement in NDI and VAS scores in the glycerol-preserved group cannot be explained but may relate to reports of possible degraded biomechanical performance by freeze-dried grafts even after a lengthy rehydration period. ${ }^{4,11,22}$

Murrey et al. ${ }^{21}$ performed a randomized controlled study comparing ACDF and disc replacement surgery. Patients in the allograft group reported decreases from baseline NDI scores: 22.5 at 3 months and 26.4 at 6 months. These de- 


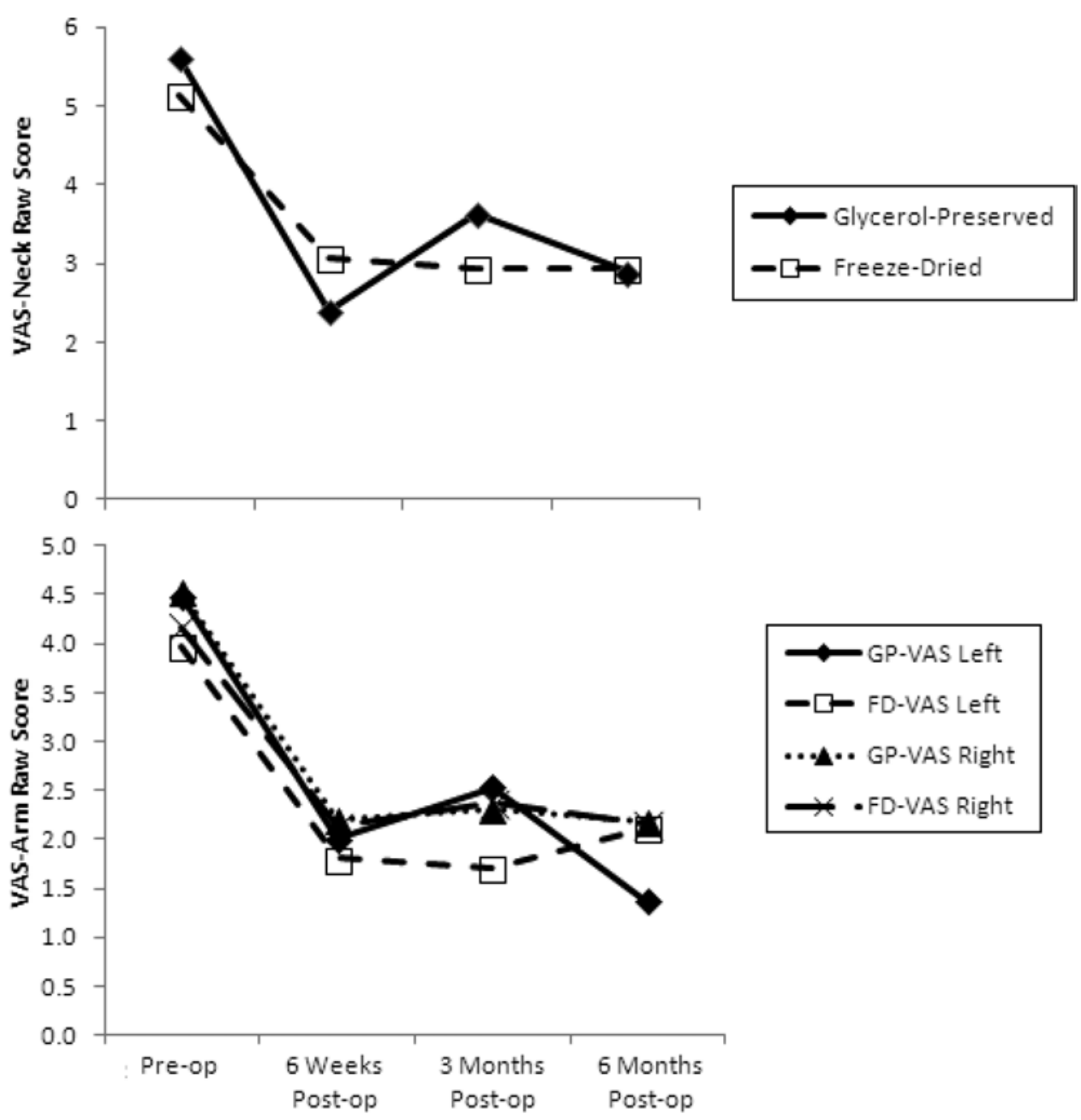

FIG. 5. Neck (upper) and arm (lower) VAS scores for glycerol-preserved (GP) and freeze-dried (FD) allograft groups. The arm scores refer to both left and right arms. Scores in both groups decreased in a similar manner.

creases in NDI scores compare favorably to our findings for the glycerol-preserved group whose decrease from baseline was 20.2 at 3 months and 24.99 at 6 months. The NDI scores for patients in the freeze-dried group did not decrease as much, with a decrease from baseline of 13.86 and 15.03 at 3 and 6 months, respectively.

Additionally, Seng et al..$^{25}$ performed a prospective 2-year follow-up of 116 patients with cervical myelopathy treated using 2 different approaches: ACDF in a group composed of 23 allograft patients and 41 autograft patients, and posterior laminoplasty in 52 patients. At the 6-month follow-up, patients in the ACDF group reported a decrease of $19.1 \pm 22.5$ from baseline NDI scores and $2.2 \pm 3.8$ from baseline VAS-neck scores. The VAS-neck data were scaled to a 10 -point scale to allow for a more accurate comparison. Again, these results compare favorably to our findings for glycerol-treated allografts at 6 months, that is, a decrease of 24.99 from baseline NDI scores and 2.72 from baseline VAS-neck scores. Patients who had received freeze-dried grafts had a smaller decrease of 15.03 and 2.2 from baseline NDI and VAS-neck scores, respectively, but these results were still comparable to those in the Seng et al. study.
Although the focus of this study was on the allograft preservation method, it is worthwhile to note that the qualitatively assessed fusion rate of $>95 \%$ after using Cloward dowels compares favorably with the documented allograft fusion rates of 78\%-94\% after using the Smith-Robinson technique. ${ }^{5,35}$ The results also compare well with the combined "overall success" rates of $72 \%-85 \% \%^{9,20}$ seen in cervical total disc replacement (CTDR), although the validity of the overall success metric used as well as the noninferiority design of CTDR studies has been questioned ${ }^{36}$ Neither did our study focus on cost-effectiveness; however, a brief comparison based on our approximate hospital cost for a 1-level treatment is shown in Table 3. Given the considerable cost variation for the different treatment methods, further investigation using comparative effectiveness methodology may be warranted.

While freeze-dried allografts have been an attractive option to diminish the difficulties of transporting, storing, and thawing traditionally processed frozen grafts, problems with this treatment do exist. One issue of concern is the reported brittleness or graft fracture that can manifest upon graft insertion. ${ }^{4,11}$ Furthermore, freeze-dried cortical allografts have been biomechanically weaker than 
TABLE 3. Approximate hospital implant cost for treating 1 cervical motion segment*

\begin{tabular}{lclc}
\hline \multicolumn{1}{c}{ Procedure } & Allograft Cost & \multicolumn{1}{c}{ Hardware Cost } & Total Cost \\
\hline ACDF Cloward & $\$ 700$ & $\$ 1000$ (1 plate, 4 screws, 1 drill bit) & $\$ 1700$ \\
\hline ACDF Smith-Robinson & $\$ 800$ & $\$ 1150$ (1 plate, 4 screws, 1 drill bit, 2 distracting pins) & $\$ 1950$ \\
\hline Synthes Zero P & NA & $\$ 3000$ (1 peek spacer, 4 screws) & $\$ 3000$ \\
\hline CTDR Synthes ProDisc-C & NA & $\$ 4725$ (1 TDR pro) & $\$ 4725$ \\
\hline
\end{tabular}

$\mathrm{NA}=$ not applicable

* Data obtained within the Medical College of Virginia.

frozen allografts, even after rehydration. ${ }^{22}$ However, as reported in a biomechanical study, ${ }^{27}$ the percentage strain exhibited by glycerol-preserved grafts was approximately equivalent to that exhibited by the frozen grafts, which suggests glycerol preservation maintains the native properties of bone. In contrast, the freeze-dried grafts were more brittle with a lower modulus of rupture, and even 60 minutes of rehydration was insufficient to recover the original properties of the graft. In a separate study, ${ }^{19}$ it was shown that glycerol storage also maintains compressive properties of bone allografts comparably to traditionally treated bone allografts.

The ease of use, preservation of biomechanical, antimicrobial ${ }^{10,23,24,33}$ and viral inactivation properties ${ }^{10,17,18,32}$ of glycerol preservation make it a potentially advantageous allograft treatment choice. Our purpose in this study was to investigate, in clinical application, whether glycerol-preserved bone grafts would perform successfully in ACDF surgery. We found that glycerol-preserved Cloward dowels had clinical results equivalent to those of freeze-dried Cloward dowels. By 6 months postimplantation, 46 of 47 patients with glycerol-preserved grafts had fully intact grafts, with only 2 patients having signs of subsidence. Thirty-seven of 39 patients with freeze-dried grafts had fully intact grafts, with only 2 patients showing signs of subsidence.

This study is limited by several factors. A cost comparison was not made between sample groups. Given the general equivalence in outcomes, we expected treatment costs might be similar. The cost of each type of allograft from the manufacturer was similar regardless of the preservation method, although additional shipping and storage costs would be expected with the frozen grafts. However, the time savings in using the glycerol-preserved grafts versus the rehydration-required freeze-dried grafts is a valid consideration. Moreover, the possibility of avoiding the costs associated with potential frozen-graft discards because of improper shipping or storage could be significant. We also studied only one type of graft (Cloward dowel) and in one location-specific procedure (ACDF). Despite this limitation, our results may be instructive to the use of other glycerol-preserved allografts in spinal surgery. While the study dropout rate was higher than desired, the operating surgeons have decades of combined experience performing this procedure; thus, it is unlikely that clinical dissatisfaction explains the higher rate, but rather the nature of the study population. Finally, although multiple surgeons treated the patients, all of the patients were seen at the same location using the same procedure; therefore, the results would be more generalizable with a multicenter study involving additional spinal approaches and the use of other structural allograft constructs.

\section{Conclusions}

Glycerol-preserved allografts exhibited fusion outcomes, subsidence measurements, adverse event reports, and functional outcome scores similar to those demonstrated by freeze-dried grafts used in ACDF surgery. These results, in addition to the glycerol-preserved allograft's maintenance of biomechanical properties and ease of preparation, support its use in ACDF procedures.

\section{Acknowledgments}

We acknowledge special assistance in this study from Amanda McCluskey (formerly of Medical College of Virginia), Patricia Leach (Medical College of Virginia), Tyler Trapani (LifeNet Health), and Liisa Eisenlohr and Katrina Ruth (both formerly of LifeNet Health).

\section{References}

1. Balsly CR, Cotter AT, Williams LA, Gaskins BD, Moore MA, Wolfinbarger L Jr: Effect of low dose and moderate dose gamma irradiation on the mechanical properties of bone and soft tissue allografts. Cell Tissue Bank 9:289-298, 2008

2. Bertalanffy H, Eggert HR: Complications of anterior cervical discectomy without fusion in 450 consecutive patients. Acta Neurochir (Wien) 99:41-50, 1989

3. Bishop J, Moore KA, Hadley MN: Anterior cervical interbody fusion using autogeneic and allogeneic graft substrate: a prospective comparative analysis. J Neurosurg 85:206-210, 1996

4. Bolesta MJ, Rechtine GR II, Chrin AM: Three- and four-level anterior cervical discectomy and fusion with plate fixation: a prospective study. Spine (Phila Pa 1976) 25:2040-2046, 2000

5. Bottino MC, Jose MV, Thomas V, Dean DR, Janowski GM: Freeze-dried acellular dermal matrix graft: effects of rehydration on physical, chemical, and mechanical properties. Dent Mater 25:1109-1115, 2009

6. Brown MD, Malinin TI, Davis PB: A roentgenographic evaluation of frozen allografts versus autografts in anterior cervical spine fusions. Clin Orthop Relat Res (119):231-236, 1976

7. Buttermann GR: Prospective nonrandomized comparison of an allograft with bone morphogenic protein versus an iliaccrest autograft in anterior cervical discectomy and fusion. Spine J 8:426-435, 2008

8. Cloward RB: The anterior approach for removal of ruptured cervical disks. J Neurosurg 15:602-617, 1958

9. Coric D, Nunley PD, Guyer RD, Musante D, Carmody CN, 
Gordon CR, et al: Prospective, randomized, multicenter study of cervical arthroplasty: 269 patients from the KineflexIC artificial disc investigational device exemption study with a minimum 2-year follow-up. Clinical article. J Neurosurg Spine 15:348-358, 2011

10. de Backere AC: Euro Skin Bank: large scale skin-banking in Europe based on glycerol-preservation of donor skin. Burns 20 (Suppl 1):S4-S9, 1994

11. de Roeck NJ, Drabu KJ: Impaction bone grafting using freeze-dried allograft in revision hip arthroplasty. J Arthroplasty 16:201-206, 2001

12. Edwards CC II, Karpitskaya Y, Cha C, Heller JG, Lauryssen C, Yoon ST, et al: Accurate identification of adverse outcomes after cervical spine surgery. J Bone Joint Surg Am 86-A:251-256, 2004

13. Goldberg G, Hilibrand A: Anterior cervical discectomy and fusion. Oper Tech Orthop 13:188-194, 2003

14. Ikenaga M, Shikata J, Tanaka C: Radiculopathy of C-5 after anterior decompression for cervical myelopathy. J Neurosurg Spine 3:210-217, 2005

15. Lee MJ, Bazaz R, Furey CG, Yoo J: Influence of anterior cervical plate design on dysphagia: a 2-year prospective longitudinal follow-up study. J Spinal Disord Tech 18:406-409, 2005

16. Lee MJ, Bazaz R, Furey CG, Yoo J: Risk factors for dysphagia after anterior cervical spine surgery: a two-year prospective cohort study. Spine J 7:141-147, 2007

17. Marshall L, Ghosh MM, Boyce SG, MacNeil S, Freedlander E, Kudesia G: Effect of glycerol on intracellular virus survival: implications for the clinical use of glycerol-preserved cadaver skin. Burns 21:356-361, 1995

18. Moore MA: Inactivation of enveloped and non-enveloped viruses on seeded human tissues by gamma irradiation. Cell Tissue Bank 13:401-407, 2012

19. Moore MA, Balsly CR, Ruth KL, Wolfinbarger L: The effects of an alternate preservation method on the biomechanical strength of allograft tissue. Paper presented at the Annual Meeting of the Orthopedic Research Society, Poster No. 1067, San Francisco, CA, 2008. Orthopaedic Research Society. (Poster) (http://www.ors.org/Transactions/54/1067.pdf) [Accessed September 23, 2014]

20. Murrey D, Janssen M, Delamarter R, Goldstein J, Zigler J, Tay B, et al: Results of the prospective, randomized, controlled multicenter Food and Drug Administration investigational device exemption study of the ProDisc-C total disc replacement versus anterior discectomy and fusion for the treatment of 1-level symptomatic cervical disc disease. Spine J 9:275-286, 2009

21. Murrey DB, Janssen ME, Odum SM, Gottlieb JR, Spector LR, Darden BV: Two-year results of a randomized controlled clinical trial comparing ProDisc-c and anterior cervical discectomy and fusion. SAS J 2:76-85, 2008

22. Nather A, Thambyah A, Goh JC: Biomechanical strength of deep-frozen versus lyophilized large cortical allografts. Clin Biomech (Bristol, Avon) 19:526-533, 2004

23. Pianigiani E, Ierardi F, Cuciti C, Brignali S, Oggioni M, Fimiani M: Processing efficacy in relation to microbial contamination of skin allografts from 723 donors. Burns 36:347-351, 2010

24. Saegeman VS, Ectors NL, Lismont D, Verduyckt B, Verhaegen J: Short- and long-term bacterial inhibiting effect of high concentrations of glycerol used in the preservation of skin allografts. Burns 34:205-211, 2008

25. Seng C, Tow BP, Siddiqui MA, Srivastava A, Wang L, Yew AK, et al: Surgically treated cervical myelopathy: a functional outcome comparison study between multilevel anterior cervical decompression fusion with instrumentation and posterior laminoplasty. Spine J 13:723-731, 2013

26. Smith-Hammond CA, New KC, Pietrobon R, Curtis DJ, Scharver $\mathrm{CH}$, Turner DA: Prospective analysis of incidence and risk factors of dysphagia in spine surgery patients: comparison of anterior cervical, posterior cervical, and lumbar procedures. Spine (Phila Pa 1976) 29:1441-1446, 2004

27. Sohoni P, Morris AR, Balsly CR, Cotter AT, Sander TW: The effects of a new preservation method on the biomechanics and shelf life of allograft bone. Presented at the Annual Meeting of the Orthopedic Research Society, Poster No. 1452, Long Beach, CA, 2011. Orthopaedic Research Society. (Poster) (http://www.ors.org/Transactions/57/1452.pdf) [Accessed September 23, 2014]

28. Tew JM Jr, Mayfield FH: Complications of surgery of the anterior cervical spine. Clin Neurosurg 23:424-434, 1976

29. Torrens MJ, Miliaras G: Cervical spondylosis. Part II: Surgical management. Curr Orthop 16:300-310, 2002

30. Tye GW, Graham RS, Broaddus WC, Young HF: Graft subsidence after instrument-assisted anterior cervical fusion. J Neurosurg 97 (2 Suppl):186-192, 2002

31. Vaidya R, Carp J, Sethi A, Bartol S, Craig J, Les CM: Complications of anterior cervical discectomy and fusion using recombinant human bone morphogenetic protein-2. Eur Spine J 16:1257-1265, 2007

32. van Baare J, Buitenwerf J, Hoekstra MJ, du Pont JS: Virucidal effect of glycerol as used in donor skin preservation. Burns 20 (Suppl 1):S77-S80, 1994

33. van Baare J, Ligtvoet EE, Middelkoop E: Microbiological evaluation of glycerolized cadaveric donor skin. Transplantation 65:966-970, 1998

34. Zaveri GR, Ford M: Cervical spondylosis: the role of anterior instrumentation after decompression and fusion. J Spinal Disord 14:10-16, 2001

35. Zdeblick TA, Ducker TB: The use of freeze-dried allograft bone for anterior cervical fusions. Spine (Phila Pa 1976) 16:726-729, 1991

36. Zechmeister I, Winkler R, Mad P: Artificial total disc replacement versus fusion for the cervical spine: a systematic review. Eur Spine J 20:177-184, 2011

\section{Author Contributions}

Conception and design: Graham, Moore, Mathern. Acquisition of data: Graham, Samsell, Moore, Stary, Vega, Mathern. Analysis and interpretation of data: all authors. Drafting the article: Graham, Samsell, Moore, Mathern. Critically revising the article: all authors. Reviewed submitted version of manuscript: all authors. Approved the final version of the manuscript on behalf of all authors: Graham. Statistical analysis: Samsell, Proffer. Administrative/technical/material support: Graham, Samsell, Proffer, Moore, Mathern. Study supervision: Graham, Moore, Mathern.

\section{Supplemental Information}

\section{Previous Presentation}

Portions of this work were presented in poster form at the 2013 Congress of Neurological Surgeons Annual Meeting held in San Francisco, California, on October 19-23, 2013.

\section{Correspondence}

R. Scott Graham, Department of Neurosurgery, Virginia Commonwealth University Health Systems, 417 N. 11th St., 6th Fl., Richmond, VA 23298. email: rgraham@mcvh-vcu.edu. 